\title{
Submicroscopic crystals in osteoarthritic synovial fluids
}

\author{
Angela Swan, Barry Chapman, Peter Heap, Heather Seward, Paul Dieppe
}

\begin{abstract}
Objectives-To investigate the hypothesis that synovial fluid (SF) from patients with osteoarthritis (OA) may contain calcium phosphate crystals that are either too small, or too few in number to be identified by conventional light microscopy techniques.

Methods-Twelve SF from 11 patients with established knee $O A$, five SF from patients with rheumatoid arthritis (RA), and two control samples of SF from patients with pseudogout were subjected to an enzyme/hypochlorite extraction procedure. The patients with $O A$ and $R A$ had no radiographic evidence of chondrocalcinosis, or SF crystals on polarised light microscopy. Extracted material was examined and analysed by analytical electron microscopy (AEM) and $x$ ray powder diffraction (XRD).

Results-Mineral was found in 11 of $12 \mathrm{OA}$ samples, ranging from 2-120 $\mathrm{\mu g} / \mathrm{ml}$ SF. Analytical electron microscopy revealed calcium pyrophosphate dihydrate (CPPD) crystals in five (confirmed by $X R D$ in three) and basic calcium phosphates (BCP) in eight (five on XRD). Two samples with confirmed CPPD contained some rods with a mean length below $100 \mathrm{~nm}$. The majority of BCP clusters were also less than $100 \mathrm{~nm}$ in diameter. BCP was detected in 1/5 RA samples. Control samples contained CPPD crystals of the expected size range of 0.42-17.9 $\mu \mathrm{m}$.

Conclusions-The data indicate that many OA SF may contain CPPD or BCP crystals which are too small or too few in number to be identified by conventional techniques. Crystal deposition is not an 'on-off' phenomenon in OA.
\end{abstract}

(Ann Rheum Dis 1994; 53: 467-470)

Crystals of calcium pyrophosphate dihydrate (CPPD: $\mathrm{Ca}_{2} \mathrm{P}_{2} \mathrm{O}_{7} 2 \mathrm{H}_{2} \mathrm{O}$ ), and basic calcium phosphates (BCP), ${ }^{1}$ are frequently detected in the synovial fluid (SF) of patients with osteoarthritis (OA). BCP is thought to be a mixture of hydroxyapatite (HAP: $\mathrm{Ca}_{10}$ $\left.\left(\mathrm{PO}_{4}\right)_{6}(\mathrm{OH})_{2}\right)$ in partially substituted carbonated form, octacalcium phosphate (OCP: $\left.\mathrm{Ca}_{8} \mathrm{H}_{2}\left(\mathrm{PO}_{4}\right)_{6} 5 \mathrm{H}_{2} \mathrm{O}\right)$ and possibly tricalcium phosphate $\left(\mathrm{Ca}_{3}\left(\mathrm{PO}_{4}\right)_{2}\right)$. BCP crystals fre- quently coexist with CPPD. It is not clear what role crystals play in the pathogenesis of OA, although some association between severity of $\mathrm{OA}$ and the presence of BCP crystals has been recorded, ${ }^{2}$ and a recent report suggests some difference in expression of knee OA in those with or without CPPD crystals. ${ }^{3}$

Routine detection of birefringent SF crystals is carried out by means of polarised light microscopy. In some laboratories a staining method using Alizarin red $\mathrm{S}^{4}$ is used to detect aggregates of HAP; the individual crystals are submicroscopic and only very weakly birefringent. There is, however, variation in synovial fluid analyses between different laboratories, ${ }^{5}$ and the sensitivity of the detection methods for crystals has been questioned. ${ }^{6}$ Very low concentrations of crystals may not be detected. Moreover, crystals can only be detected by light microscopy if they are sufficiently large $(>1 \mu \mathrm{m})$, or alternatively, if the tiny crystallites aggregate into clumps of a detectable size. There have been occasional case reports of the detection of CPPD crystals in SF by electron microscopy, where light microscopy had given a negative result. ${ }^{78}$ Because of difficulties with quantification, crystals in joints are usually reported as being 'present' or 'absent', that is, 'on-off' phenomenon, although some degree of gradation in crystal load probably exists. We have used a new method for extracting and quantifying calciumcontaining crystals from $\mathrm{SF}^{9}$ to investigate two hypotheses; firstly, that SF samples from a subgroup of patients with knee OA may contain small quantities of crystals, below the concentration threshold for identification by current light microscopy methods. Secondly, that these samples may contain populations of crystals too small for detection by light microscopy.

\section{Materials and methods}

PATIENT DATA AND SF SAMPLES

Patients were recruited from a hospital based rheumatology clinic; all had painful knees with large effusions requiring therapeutic aspiration and injection. Eleven patients had clinical and radiographic knee OA, fulfilling the ACR OA criteria, ${ }^{10}$ and five patients fulfilled the ACR criteria for rheumatoid arthritis (RA). ${ }^{11}$ Two patients presented with acute arthritis, radiographic evidence of chondrocalcinosis (CCA), and CPPD crystals in the inflammatory SF, leading to a diagnosis of pseudogout. $\mathrm{SF}$ was aspirated via a 21 gauge $(0 \cdot 8 \times 40 \mathrm{~mm})$ needle. 

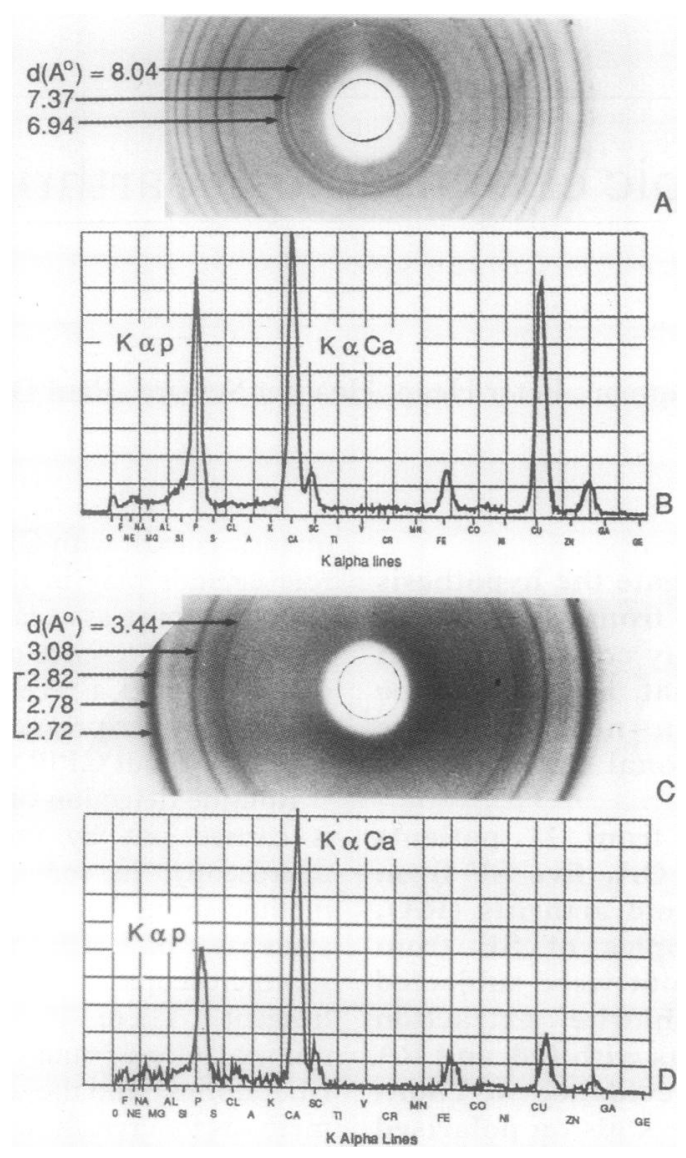

Figure $1 A$ is the central area of the $X$-ray diffraction film of extracted material from an $O A S F$ in which microcrystals only (rods and ovoids with mean length $<100 \mathrm{~nm}$ ) were detected by $A E M$. Indicated are d-spacing values $(A)$ corresponding to values for triclinic CPPD (8.04 and 6.94) and monoclinic CPPD (7-37). The reflections indicated $a$ mixture of monoclinic and triclinic CPPD; very weak reflections indicative of $H A P$ were also present. Figure $1 B$ illustrates an energy dispersive $X$-ray spectrum obtained from $a$ very small rod extracted from this same $O A S F$. The ratio of Ca:P is 1.2:1, identical to that of larger CPPD crystals extracted from 3 other $O A S F$, and to that of synthetic $C P P D$ in our system. Other rods and ovoid particles in the extracted material from this $S F$ gave a Ca:P ratio indicative of $H A P$. The copper $(\mathrm{Cu})$ peak arises from the grid supporting the extracted material. Figure $1 C$ is the central area of the $X$-ray diffraction film of extracted material from another $O A S F$, in which HAP only was identified; the $d$-spacing values $(A)$ correspond to values for $H A P$. Figure $1 D$ illustrates the energy dispersive $X$-ray spectrum of an ovoid particle extracted from this $O A S F$, the Ca:P ratio of 2.2:1 corresponding to that of synthetic HAP in our system. NB. XRD analysis: theoretical values were taken from; powder diffraction file alphabetical indexes; Inorganic phases; 1990 International centre for diffraction data, datafile numbers 28-233, 22-536 (CPPD), 9-432 (HAP).

SF EXAMINATION. EXTRACTION PROCEDURE The SF samples were examined for birefringent crystal content by polarised light microscopy and 'scored' for HAP/BCP content by an alizarin red $S$ staining method, ${ }^{12}$ by the same experienced observer. No identifiable birefringent crystals were detected in any of the OA or RA samples. The OA and RA samples were all scored negative for HAP/BCP content. The two pseudogout samples contained many CPPD crystals, one also scoring positive for HAP/BCP content. The SF samples (stored unspun at $-70^{\circ} \mathrm{C}$ for up to two weeks before processing), were subjected to the validated enzyme/hypochlorite extraction procedure described by Swan et al. ${ }^{9}$

DETECTION OF ANALYSIS OF CRYSTALS

Extracted material was weighed on a Cahn 21 microbalance, and examined and analysed in a Jeol 200 CX TEM/SCAN analytical electron microscope, fitted with a Kevex 5000A and $6000 x$ ray energy spectrometer system. The mean size of crystals was calculated from measurements from electron micrographs. When sufficient material was available, analysis was carried out by $x$ ray powder diffraction (XRD) (PW 1010/80 Phillips $x$ ray generator: $\mathrm{Cu} \mathrm{K}$ alpha radiation plus nickel filter, with a Debye-Scherrer powder camera $(114.83 \mathrm{~mm}$ diameter)) (figure).

\section{Results}

Patients and SF data are summarised in table 1. Extraction and crystal analysis data are summarised in table 2 . No CPPD crystals were identified in any of the five RA samples; only one RA sample contained calcium phosphate crystals, subsequently identified as HAP by both energy dispersive $x$ ray analysis (EDXA) and XRD. The quantity of extracted material was small, $<8 \mu \mathrm{g}$ of extracted material per $\mathrm{ml}$ $\mathrm{SF}$, with evidence of some residual organic material present, although the extracted crystalline material was sufficiently protein-free for a powder diffraction pattern to be otained. Calcium carbonate in the form of calcite crystals was identified by XRD analysis in one RA sample. The calcite might be artefactual, having formed early in sample storage.

In contrast, 11 of $12 \mathrm{SF}$ samples from the OA group contained calcium phosphate crystals. The patients were unusual in having large volume effusions, possibly indicative of low-grade inflammation, although the white cell estimate was low in all except one of our samples. The yield of extracted crystalline

Table 1 Patient and synovial fluid data

\begin{tabular}{|c|c|c|c|c|c|c|}
\hline Diagnosis & Sex & $\begin{array}{l}\text { Mean }(S D) \\
\text { age } \\
\text { Range }\end{array}$ & $\begin{array}{l}\text { Disease duration } \\
\text { Mean (SD) years } \\
\text { Range }\end{array}$ & $\begin{array}{l}\text { Mean (SD) synovial } \\
\text { fluid volume (ml) } \\
\text { Range }\end{array}$ & $\begin{array}{l}\text { Synovial fluid } \\
\text { crystals by light } \\
\text { microscopy }\end{array}$ & $\begin{array}{l}\mathrm{x} \text { ray } \\
C C A\end{array}$ \\
\hline $\begin{array}{l}\text { Osteoarthritis } \\
\mathrm{n}=11 \\
\text { Rheumatoid arthritis } \\
\mathrm{n}=5 \\
\text { Pseudogout } \\
\mathrm{n}=2\end{array}$ & $\begin{array}{l}7 \text { Male, } 4 \text { Female } \\
1 \text { Male, } 4 \text { Female } \\
1 \text { Male, } 1 \text { Female }\end{array}$ & $\begin{array}{l}65(9) \\
49 \text { to } 75 \\
52(18) \\
21 \text { to } 66 \\
1) 81 \\
2) 78 \\
\end{array}$ & $\begin{array}{l}11(9) \\
<1 \text { to } 24 \\
19(15) \\
2 \text { to } 33 \\
\text { 1) } 10 \\
\text { 2) } 4\end{array}$ & $\begin{array}{l}41(24) \\
20 \text { to } 105 \\
32(16) \\
20 \text { to } 55 \\
\text { 1) } 32 \\
\text { 2) } 20\end{array}$ & $\begin{array}{l}\text { All no } \\
4 / 5 \text { no } \\
1 / 5^{\star} \\
\text { 1)CPPD } \\
\text { 2)CPPD + BCP }\end{array}$ & $\begin{array}{l}\text { All no } \\
\text { All no } \\
\text { Both yes }\end{array}$ \\
\hline
\end{tabular}

Synovial fluid crystals $=$ Number of patients positive for crystals in synovial fluid by microscopy + staining. Crystals identified as CPPD and/or BCP.

* = unidentified irregular birefringent crystals.

$x$ ray CCA $=$ radiographic evidence of chondocalcinosis.

NB One patient in the osteoarthritis group had a history of osteoarthritis only, but presented with an unexplained inflammatory episode on this occasion. No crystals were detected in synovial fluid by light microscopy + staining. 
Table 2 Summarises white cell estimate, extraction data and analysis data (when available) for all 18 samples. Column 4 indicates the presence of crystals (regular rods, ovoids) in the extracted deposit having a Ca:P ratio of 1.2:1, identical to that of CPPD in our system, and/or a Ca:P ratio of $2.2: 1$, identical to that of HAP in our system (EDXA analysis). In some samples, different Ca:P ratios, indicating the possible presence of other calcium phosphate crystals, were also obtained by EDXA analysis. The mean size of hexagonal/ovoid HAP crystals, of large CPPD rods, and of small rods (either HAP needles, or possibly very small CPPD rods) is also given. Where there were insufficient crystals for mean values to be calculated, an approximate indication of crystal size is given

\begin{tabular}{|c|c|c|c|c|c|c|}
\hline \multirow{2}{*}{$\begin{array}{l}\text { Patient } \\
\text { Diagnosis }\end{array}$} & \multirow{2}{*}{$\begin{array}{l}W C E \times \\
10^{5} / \mathrm{ml}\end{array}$} & \multirow{2}{*}{$\begin{array}{l}\text { Weight } \\
\text { extracted } \\
\text { material } \\
\mu \mathrm{g} / \mathrm{mlSF}\end{array}$} & \multirow{2}{*}{$\begin{array}{l}\text { Crystals } \\
\text { identified by } \\
\text { AEM }\end{array}$} & \multirow{2}{*}{$\begin{array}{l}\text { Crystals } \\
\text { identified by } \\
X R D\end{array}$} & \multicolumn{2}{|c|}{ AEM. Mean size of crystals } \\
\hline & & & & & $\begin{array}{l}\text { Rods } n m \\
\text { SD range }\end{array}$ & $\begin{array}{l}\text { Hexagonal } n m \\
S D \text { range }\end{array}$ \\
\hline $\mathrm{OA}$ & FEW & 7 & $\begin{array}{l}\text { CPPD } \\
\text { HAPS }\end{array}$ & $\begin{array}{l}\text { HAP } \\
\text { (CPPD) }\end{array}$ & $\begin{array}{l}62(21) \\
39-98\end{array}$ & $\begin{array}{l}75(42) \\
39-40\end{array}$ \\
\hline $\mathrm{OA}$ & $<1$ & 4 & HAPS & HAP & $\begin{array}{l}37(19) \\
18-81\end{array}$ & $\simeq 60$ \\
\hline $\begin{array}{l}\text { OA } \\
\text { OA }\end{array}$ & $\begin{array}{l}1 \\
1\end{array}$ & $\begin{array}{r}3 \\
10\end{array}$ & $\begin{array}{l}\text { None } \\
\text { HAPS }\end{array}$ & $\begin{array}{l}\text { None } \\
\text { HAP }\end{array}$ & $\begin{array}{l}46(28) \\
20-120\end{array}$ & $\begin{array}{l}40(11) \\
25-65\end{array}$ \\
\hline $\begin{array}{l}\text { OA } \\
\text { OA }\end{array}$ & $\begin{array}{r}1 \\
<1\end{array}$ & $\begin{array}{c}10 \\
120 \dagger\end{array}$ & $\begin{array}{l}\text { HAP } \\
\text { HAP }\end{array}$ & $\begin{array}{l}\text { None } \\
\text { HAP }\end{array}$ & & \\
\hline $\mathrm{OA}$ & $<1$ & 10 & $\begin{array}{l}\text { CPPD } \\
\text { HAP }\end{array}$ & CPPD & $\begin{array}{l}28(13) \\
10-57\end{array}$ & $\begin{array}{l}54(17) \\
22-87\end{array}$ \\
\hline $\begin{array}{l}\text { OA } \\
\text { OA }\end{array}$ & $\stackrel{1}{117^{\star}}$ & $\begin{array}{r}5 \\
20\end{array}$ & $\begin{array}{l}\text { CPPD } \\
\text { CPPD } \\
\text { Unknown }\end{array}$ & $\begin{array}{l}\text { None } \\
\text { CPPD } \\
\text { Unknown }\end{array}$ & $\begin{array}{l}>4500 \\
>7500\end{array}$ & \\
\hline $\begin{array}{l}\text { OA } \\
\text { OA } \\
\text { OA } \\
\text { RA } \\
\text { RA } \\
\text { RA } \\
\text { RA } \\
\text { RA } \\
\text { PG }\end{array}$ & $\begin{array}{r}2 \\
5 \\
2 \\
25 \\
20 \\
38 \\
20 \\
24 \\
10\end{array}$ & $\begin{array}{c}2 \\
10 \\
10 \\
2 \dagger \\
2 \dagger \\
7 \dagger \\
2 \dagger \\
8 \dagger \\
100\end{array}$ & $\begin{array}{l}\text { HAP } \\
\text { CPPD } \\
\text { HAPS } \\
\text { None } \\
\text { None } \\
\text { None } \\
\text { None } \\
\text { HAP } \\
\text { CPPD }\end{array}$ & $\begin{array}{l}\text { HAP } \\
\text { None } \\
\text { None } \\
\text { None } \\
\text { None } \\
\text { Calcite } \\
\text { None } \\
\text { HAP } \\
\text { CPPD }\end{array}$ & $\begin{array}{l}3740(1580) \\
2360-6490 \pm\end{array}$ & \\
\hline PG & 25 & 2599 & $\begin{array}{l}\text { CPPD } \\
\text { HAP }\end{array}$ & $\begin{array}{l}\text { CPPD } \\
\text { (HAP) }\end{array}$ & $\begin{array}{l}8370(4190) \\
1320-17900 \ddagger\end{array}$ & $20-70$ \\
\hline
\end{tabular}

WCE = white cell estimate. (High WCE, predominantly PMN cells).

${ }^{\star} \mathrm{OA}$ SF + high WCE; deposit having a very few CPPD + unidentified crystals.

†Extracted material = brownish powder. Creamish powder was extracted from other OA SF, and white powder from the two PG SF. $\ddagger$ Rhomboidal CPPD crystals (size $420-3550 \mathrm{~nm}$ ) also frequently indentified in two PG samples; none were detected in the OA SF. SAEM analysis suggested calcium phosphate crystals other than CPPD or HAP present.

material was less than $15 \mu \mathrm{g}$ of creamish-white powder per $\mathrm{ml} \mathrm{SF}$ in 11 of 12 OA samples. A very few 'large' CPPD rods (that is $>1 \mu \mathrm{m}$ long) were detected by EM/EDXA in three samples where the original SF was scored negative for CPPD by light microscopy. In two other samples from OA patients, no 'large' CPPD crystals were detected but EM/EDXA revealed small rods/needles some below $100 \mathrm{~nm}$ in association with ovoid particles (possibly hexagonal but the exact form was indistinct). EDXA Ca:P ratios indicated that some of these small rods were CPPD crystals; other needles and ovoids were HAP; the presence of CPPD was confirmed by XRD in one of these samples. HAP crystals were identified in 8 of $12 \mathrm{OA}$ samples, coexisting with CPPD in three of these. There was evidence of crystals with a $\mathrm{Ca}: \mathrm{P}$ ratio differing from that of CPPD or HAP, in some OA samples. This might indicate the presence of OCP, or Ca deficient apatite. No magnesium was detected in any of the samples; the magnesium-substituted $\beta$-tricalcium phosphate identified in joint tissues by some authors ${ }^{13}$ was absent.

\section{Discussion}

This study was designed to use a recently developed extraction process, together with analytical techniques, to establish whether a small group of patients with knee OA might have SF crystals that are either too few in number, or too small, to be detected by established light microscopy procedures. Five SF samples from patients with RA, and two psuedogout samples were processed for comparison purposes. The expected finding of large quantities of large $(0.42$ to $17.9 \mu \mathrm{m})$ CPPD crystals in the pseudogout samples fits with published data to suggest that crystals survive the extraction technique.

This group of OA patients was both small, and unrepresentative in that all the SF samples were of large volume (necessary to extract sufficient quantities of any crystals for further analysis). However, the study has resulted in two findings. Firstly, the results suggest the presence of a population of extremely small CPPD crystals in some OA SF; these crystals are much smaller than CPPD crystals routinely identified in joint fluid. This finding of two populations of SF CPPD crystals of entirely different size range, might suggest a difference in origin, or a different process forming the large and small crystals. Secondly, this study shows that submicroscopic crystals, or very low concentrations of crystals, may be present in OA SF, when careful light microscopy has given a negative result. It is possible that most OA SF samples may contain small quantities of calcium-containing crystals, and it is suggested that for patients with $O A$ the delineation between 'crystal' and 'non-crystal' arthropathy is an artificial one.

We thank Dr Brigid Heywood, Department of Chemistry, University of Salford, for expert assistance with AEM, and Dr Peter Shellis, MRC Research Unit, Bristol Dental Hospital, for supplying synthetic HAP and OCP crystals.

The study was supported by Grants from the Arthritis and The study was supported by Grants from the Arthritis and
Rheumatism Council, and the South Western Regional Health Authority.

1 Gibilisco P A, Schumacher H R, Hollander J L, Soper K A. Synovial fluid crystals in osteoarthritis. Arthritis Rheum 1985; 28: 511-5. 
2 Halverson P, McCarty D J. Patterns of radiographic abnormalities associated with basic calcium phosphate and calcium pyrophosphate dihydrate crystal deposition in the knee. Ann Rheum Dis 1986; 45: 603-5.

3 Pattrick M, Hamilton E, Wilson R, Austin S, Doherty M. Association of radiographic changes in osteoarthritis, symptoms, and synovial fluid particles in 300 knees. Ann Rheum Dis 1993; 52: 97-103.

4 Paul H, Reginato A J, Schumacher H R. Alizarin red S staining as a screening test to detect calcium compounds
in synovial fluid. Arthritis Rheum 1983; 26: 191-200.

5 Hasselbacher P. Variation in synovial fluid analyses by hospital laboratories. Arthritis Rheum 1987; 30: 637-42.

6 Gordon C, Swan A, Dieppe P A. Detection of crystals in sordon C, Swan A, Dieppe P A. Detection of crystals in
synovial fluids by light microscopy; sensitivity and reliability. Ann Rheum Dis 1989; 48: 737-42.

7 Honig S, Gorevic P, Hoffstein S, Weissman G. Crystal deposition disease. Diagnosis by electron microscopy. $A m$ f Med 1977; 63: 161-4.

8 Bjelle A, Crocker P, Willoughby D. Ultramicrocrystals in pyrophosphate arthropathy. Crystal identification and case reports. Acta Med Scanda 1980; 207: 89-92.

9 Swan A J, Heywood B R, Dieppe P A. Extraction of calcium containing crystals from synovial fluids and articular cartilage. $\mathcal{F}$ Rheumatol 1992; 19: 1763-73.

10 Altman R, Asch E, Bloch D, et al. Development of criteria for the classification and reporting of osteoarthritis. Classification of osteoarthritis of the knee. Arthritis Rheum 1986; 29: 1039-49.

11 The American Rheumatism Association 1987, Arnett, et al. Revised criteria for the classification of rheumatoid Revised criteria for the classification of
arthritis. Arthritis Rheum 1988; 31: 315-24.

12 Swan A, Dieppe P A. Hunting for apatite crystals in synovial fluid. In: Klippel J H, Dieppe P A, eds. Rheumatology. London: Mosby, 1993: Section 7:16.

13 McCarty D J, Lehr J R, Halverson P B. Crystal populations in human synovial fluid. Identification of apatite, octocalcium phosphate and tricalcium phosphate. Arthritis Rheum 1983; 26: 1220-4. 